\title{
Editorial
}

\section{Clinical Management after Endoscopic Submucosal Dissection for Early Gastric Cancer: Sticking to the Gastroenterologist May Be the Best Option!}

\author{
Pedro Barreiro Miguel Bispo \\ Gastroenterology Department, Hospital Egas Moniz, Centro Hospitalar de Lisboa Ocidental, Lisbon, Portugal
}

\section{Key Words}

Dissection - Gastrointestinal endoscopy - Gastric mucosa • Stomach neoplasms

\section{Abordagem Clínica Após Disseção Endoscópica da Submucosa no Cancro Gástrico Precoce: Manter Seguimento pelo Gastrenterologista Poderá Ser a Melhor Opção!}

\section{Palavras Chave}

Disseção · Endoscopia gastrointestinal · Mucosa gástrica · Neoplasias gástricas

Gastric cancer is still one of the most common neoplasms worldwide. Early gastric cancer (EGC) is defined as gastric cancer confined to the mucosa or submucosa irrespective of nodal status, normally with a good prognosis $[1,2]$.

In the last 2 decades, with the development of endoscopic submucosal dissection (ESD) in Japan, a revolu-

\section{KARGER}

E-Mail karger@karger.com www.karger.com/pjg
(C) 2016 Sociedade Portuguesa de Gastrenterologia Published by S. Karger AG, Basel Karger Open access

This article is licensed under the Creative Commons AttributionNonCommercial-NoDerivatives 4.0 International License (CC BYNC-ND) (http://www.karger.com/Services/OpenAccessLicense) Usage and distribution for commercial purposes as well as any distribution of modified material requires written permission. tion in the treatment of EGC has risen. The possibility of en bloc endoscopic resection regardless of lesion size, preserving the stomach's integrity, with a low complication rate, has made ESD the desired minimally invasive treatment for EGC [2]. Compared with surgery, a recent systematic review documented a lower morbidity for ESD and a similar 5-year survival [3]. These outstanding results of ESD in EGC have been observed not only in Asia but also in reference centers in Western countries $[4,5]$.

With the emergence of this new therapeutic option for EGC, new challenges have risen. In this issue of GE Port $J$ Gastroenterol, Libânio et al. [6] review their experience in a large series of ESDs for EGC (194 lesions in 164 patients) with long-term follow-up (median follow-up time, 40 months), focusing on 3 important aspects of this technique:

1. Preprocedural risk for noncurative resection/patient selection;

2. Approach to metachronous lesions;

3. Management after noncurative endoscopic resection.

This monocentric Portuguese study has the largest cohort with the longest follow-up in Europe and brings us original new data on these 3 subjects. 
Preprocedural Risk for Noncurative Resection/

Patient Selection

Only EGC with a negligible risk of lymph node metastasis (LNM) should be selected for endoscopic treatment. Therefore, only lesions that fulfill the standard or expanded criteria for curative endoscopic resection, as defined by the Japanese and European Society of Gastrointestinal Endoscopy (ESGE) guidelines, should be selected [7, 8]. These selection criteria are crucial to avoid unprofitable endoscopic resection attempts.

Although endoscopic ultrasonography is the best locoregional staging method for gastric cancer, its diagnostic accuracy in predicting invasion depth in EGC is similar to endoscopic staging by an expert endoscopist; therefore, endoscopic ultrasonography is not routinely recommended [9]. Thus, training and experience in endoscopic staging is important. Abe et al. [9] validated some endoscopic features related to deep submucosal invasion, i.e., remarkable redness, uneven surface, margin elevation, deep ulcer, and thickened or merged convergent folds. Besides those morphologic features, large tumor size $(>30 \mathrm{~mm})$ and upper or medium location in the stomach have also been pointed out as risk factors for noncurative resection [10]. Furthermore, Toyokama et al. [11] recognized, in a recent large series, that longer procedural time, inexperienced endoscopist ( $<50$ cases), and submucosal invasion cancer were also associated with a higher risk for noncurative resection. It should be noted that the combination of risk factors for noncurative resection adds up exponentially to the global risk [10]. Therefore, Hirasawa et al. [10] developed a useful risk assessment chart to predict the probability of endoscopic curability from the tumor's characteristics, for example, the probability of cure is $<40 \%$ in large, ulcerated lesions in the upper part of the stomach.

In the present study by Libânio et al., approximately $15 \%$ of the resections were noncurative, a rate similar to other reference centers [8]. Male sex, larger tumor size, longer procedural time, and more advanced histology were associated with noncurative resection on univariate analysis, but only carcinoma on preresection biopsies was identified as a significant risk factor on multivariate analysis. As stated by the authors, the documentation of carcinoma in preresection histology as an independent predictor of treatment failure is a novel and interesting finding. Preprocedural biopsies frequently underestimate a more advanced lesion, and when carcinoma is documented, this should be regarded as an additional parameter for the prediction of noncurative endoscopic resection. Im- portantly, the recognition of these risks factors for noncurative ESD should not be used to exclude lesions from endoscopic resection, although these are important parameters for the prediction of its success. Actually, these parameters are important for a better management of patients' expectations, for the selection of lesions with a higher risk for noncurative resection that should be referred to experienced ESD endoscopists, and for the prioritization of lesions with a higher probability of noncurative resection on the waiting list.

\section{Approach to Metachronous Lesions}

Unlike surgical resection, with endoscopic treatment the stomach is preserved, allowing a better quality of life. However, there is a real risk for metachronous lesions, which should be a concern after a curative endoscopic resection.

The present study by Libânio et al. had a long followup period (mean, 40 months) and documented a high incidence of metachronous lesions (mean annual incidence rate of 5\%), higher than that reported in a large multicenter study in the Asian population (mean annual incidence rate of 3.5\%) [2]. Notably, although the mean follow-up period was shorter in the Asian multicenter study (26.8 months), a linear increase over time of metachronous gastric cancers was shown, and over $90 \%$ of these lesions were effectively treated by ESD [2]. Important new data on this subject come from a recent study by Abe et al. [12], including 1,526 patients with EGC treated by ESD, with a longer follow-up period (mean, 82.2 months). In this series, 238 patients developed metachronous gastric cancer: 5-, 7-, and 10-year cumulative incidences were $9.5,13.1$, and $22.7 \%$, respectively. During this long follow-up period, there were no gastric cancer-related deaths in the 1,288 patients without metachronous lesions. In contrast, 7 patients who developed metachronous gastric cancer died because of the disease, 5 of them more than 5 years after the index ESD (endoscopic surveillance was stopped 5 years after ESD in some patients) [12]. These data suggest that the prognosis of patients with endoscopically treated EGC seems to be more affected by the occurrence of metachronous lesions than by the potential risk of LNM from their initial EGC.

Another important finding of the study by Libânio et al. was that older patients were shown to be at higher risk of metachronous gastric cancer, which, as stated by the authors, could be related to the presumably higher prevalence of preneoplastic conditions in the elderly. All these 
Table 1. Report rates of lymph node metastasis (LNM) in patients with early gastric cancer without lymphovascular invasion [7]

\begin{tabular}{lc}
\hline Tumor features & Rates of LNM \\
\hline Predominantly differentiated type, pT1a, $>3 \mathrm{~cm}$, with ulcerative finding & $3 \%(7 / 230)$ \\
Predominantly differentiated type, pT1b (SM1) and $>3 \mathrm{~cm}$ & $2.6 \%(2 / 78)$ \\
Predominantly undifferentiated type, pT1a, $>2 \mathrm{~cm}$, without ulcerative finding & $2.8 \%(6 / 214)$ \\
Predominantly undifferentiated type, pT1a, with ulcerative finding & $5.1 \%(52 / 1,014)$ \\
Predominantly undifferentiated type, pT1b (SM1) & $10.6 \%(9 / 85)$ \\
\hline
\end{tabular}

findings point out the importance of regular endoscopic surveillance, probably every year and even more than 5 years after ESD for EGC, and also the need to define specific screening strategies for groups at higher risk.

\section{Management after Noncurative Endoscopic Resection}

In patients with noncurative endoscopic resection, surgery should be considered to reduce the risk of local recurrence or LNM. However, many of these patients are old, with multiple comorbidities, and previous studies have reported that diseases other than cancer accounted for $34-37 \%$ of the total deaths in elderly patients with gastric cancer [13]. Thus, risk stratification for local recurrence or LNM after a noncurative endoscopic resection is essential for therapeutic decisions.

When the reason for noncurative resection is only $\mathrm{Rx} /$ $\mathrm{R} 1$, the main concern will be local recurrence. A recent meta-analysis [14] has shown that only $1 / 3$ of patients with $\mathrm{HMx} / \mathrm{HM} 1$ will have recurrence/residual cancer (10\% for HMx resections; $36 \%$ for HM1 resections), with a higher risk in cases of VMx/VM1 (43\%). In the same meta-analysis, the majority of HMx/HM1 resections were managed by endoscopic treatment and/or surveillance without reports of gastric cancer-related deaths or LNM [14]. In these cases, the ESGE guidelines consider endoscopic follow-up appropriate [14]. Furthermore, because of a higher rate of residual lesions and the inability to evaluate the degree of depth of invasion in VM1 cases, surgical resection should be considered in fit patients.

Regarding predictive factors for LNM and residual tumor, in a recent study by Sunagawa et al. [15], 200 patients who underwent additional surgery after noncurative endoscopic resection were analyzed. The rate of LNM was $7.5 \%$, and the rate of local residual tumor was $11.5 \%$ [15]. In multivariable analysis, lymphovascular invasion was found to be an independent risk factor for LNM (all patients with LNM had lymphovascular invasion in the resected specimens), as already reported in other series $[16,17]$. Submucosal invasion and undifferentiated type are also recognized risk factors for LNM [15-17].

In the present study by Libânio et al., after a noncurative ESD, there was no difference in survival between patients allocated to surveillance or surgery. In fact, these results are similar to 2 recent Asian studies that also did not find a significant difference in disease-specific survival between patients who underwent surveillance and those who underwent gastrectomy after noncurative ESD $[18,19]$. Taking this into account, management after a noncurative endoscopic resection should be patient tailored: both surgeons and gastroenterologists should stratify the risk for residual tumor or LNM (Table 1) and balance this with the surgical risk, which should be calculated based on surgical risk prediction models (e.g., PPOSSUM).

With the recent worldwide spread of ESD use, the number of endoscopically treated EGCs has increased remarkably. This large study by Libânio et al. brings us novel and original data on ESD and is an important contribution to the new challenges that endoscopic resection entails. Since most available studies are Asian, this European study is of particular importance. At the bottom line, as metachronous gastric cancer seems to be a major issue after ESD for EGC (the majority still amenable to endoscopic treatment) and surveillance may be an adequate option in some patients with noncurative resections, sticking to the gastroenterologist may be the best option for these patients!

\section{Disclosure Statement}

The author has no conflicts of interest to declare. 


\section{References}

1 Ohnita K, Isomoto H, Yamaguchi N, Fukuda E, Nakamura T, Nishiyama H, et al: Factors related to the curability of early gastric cancer with endoscopic submucosal dissection. Surg Endosc 2009;23:2713-2719.

2 Kato M, Nishida T, Yamamoto K, Hayashi S, Kitamura S, Yabuta T, et al: Scheduled endoscopic surveillance controls secondary cancer after curative endoscopic resection for early gastric cancer: a multicentre retrospective cohort study by Osaka University ESD Study Group. Gut 2013;62:1425-1432.

3 Kondo A, Moura E, Bernardo W, Yagi O, Moura D, Moura E, et al: Endoscopy vs surgery in the treatment of early gastric cancer: systematic review. World J Gastroenterol 2015;21:13177-13187.

4 Pimentel-Nunes P, Mourão F, Veloso N, Afonso LP, Jácome M, Moreira-Dias L, et al: Long-term follow-up after endoscopic resection of gastric superficial neoplastic lesions in Portugal. Endoscopy 2014;46:933-940.

5 Rodrigues J, Carmo J, Carvalho L, Barreiro P, Chagas C: Endoscopic submucosal dissection for gastrointestinal superficial lesions: initial experience in a single Portuguese center. GE Port J Gastroenterol 2015;22:190-197.

6 Libânio D, Pimentel-Nunes P, Afonso LP, Henrique R, Dinis-Ribeiro M: Long-term outcomes of gastric endoscopic submucosal dissection: focus on metachronous and noncurative resection management. GE Port J Gastroenterol 2017,DOI: 10.1159/000450874.

7 Ono H, Yao K, Fujishiro M, Oda I, Nimura S, Yahagi N, et al: Guidelines for endoscopic submucosal dissection and endoscopic mucosal resection for early gastric cancer. Dig Endosc 2016;28:3-15.

8 Pimentel-Nunes P, Dinis-Ribeiro M, Ponchon T, Repici A, Vieth M, De Ceglie A, et al: Endoscopic submucosal dissection: European Society of Gastrointestinal Endoscopy (ESGE) Guideline. Endoscopy 2015;47:829854.

9 Abe S, Oda I, Shimazu T, Kinjo T, Tada K, Sakamoto T, et al: Depth-predicting score for differentiated early gastric cancer. Gastric Cancer 2011;14:35-40.

10 Hirasawa K, Kokawa A, Kou R, Oka H, Maeda $S$, Tanaka K: Determining early gastric cancer lesions appropriate for endoscopic submucosal dissection trainees: a proposal related to curability. Dig Endosc 2012;24:143-147.

11 Toyokama T, Inaba T, Omote S, Okamoto A, Miyasaka R, Watanabe K, et al: Risk factors for non-curative resection of early gastric neoplasms with endoscopic submucosal dissection: analysis of 1,123 lesions. Exp Ther Med 2015;9:1209-1214.

12 Abe S, Oda I, Suzuki H, Nonaka S, Yoshinaga $\mathrm{S}$, Nakajima T, et al: Long-term surveillance and treatment outcomes of metachronous gastric cancer occurring after curative endoscopic submucosal dissection. Endoscopy 2015;47:1113-1118.

13 Moriguchi S, Maehara Y, Korenaga D, Sugimachi K, Nose Y: Relationship between age and the time of surgery and prognosis after gastrectomy for gastric cancer. J Surg Oncol 1993;52:119-123.
14 Figueiredo PC, Pimentel-Nunes P, Libânio D, Dinis-Ribeiro M: A systematic review and meta-analysis on outcomes after Rx or R1 endoscopic resection of superficial gastric cancer. Eur J Gastroenterol Hepatol 2015;27: 1249-1258.

15 Sunagawa H, Kinoshita T, Kaito A, Shibasaki H, Kaneko K, Ochiai A, et al: Additional surgery for non-curative resection after endoscopic submucosal dissection for gastric cancer: a retrospective analysis of 200 cases. Surg Today 2016, Epub ahead of print.

16 Toyokawa T, Ohira M, Tanaka H, Minamino $\mathrm{H}$, Sakurai K, Nagami Y, et al: Optimal management for patients not meeting the inclusion criteria after endoscopic submucosal dissection for gastric cancer. Surg Endosc 2016; 30:2404-2414.

17 Son SY, Park JY, Ryu KW, Eom BW, Yoon HM, Cho SJ, et al: The risk factors for lymph node metastasis in early gastric cancer patients who underwent endoscopic resection: is the minimal lymph node dissection applicable? A retrospective study. Surg Endosc 2013;27:3247-3253.

18 Yamanouchi K, Ogata S, Sakata Y, Tsuruoka N, Shimoda R, Nakayama A, et al: Effect of additional surgery after noncurative endoscopic submucosal dissection for early gastric cancer. Endosc Int Open 2016;4:E24-E29.

19 Choi J, Jeon S, Cho K, Park K, Kim E, Park G, et al: Non-curative endoscopic resection does not always lead to grave outcomes in submucosal invasive early gastric cancer. Surg Endosc 2015;29:1842-1849. 